\title{
Experiences of Ethics, Governance and Scientific Practice in Neuroscience Research
}

\author{
Martyn Pickersgill
}

\subsection{INTRODUCTION $^{1}$}

Over the last decade or so, sociologists and other social scientists concerned with the development and application of biomedical research have come to explore the lived realities of regulation and governance in science. In particular, the instantiation of ethics as a form of governance within scientific practice - via, for instance, research ethics committees (RECs) has been extensively interrogated. ${ }^{2}$ Social scientists have demonstrated the reciprocally constitutive nature of science and ethics, which renders problematic any assumption that ethics simply follows (or stifles) science in any straightforward way. ${ }^{3}$

This chapter draws on and contributes to such discussion through analysing the relationship between neuroscience (as one case study of scientific work) and research ethics. I draw on data from six focus groups with scientists in the UK (most of whom worked with human subjects) to reflect on how ethical questions and the requirements of RECs as a form of regulation are experienced within (neuro)science. The focus groups were conducted in light of a conceptual concern with how 'issues and identities interweave'; i.e. how personal and professional identities relate to how particular matters of concern are comprehended and engaged with, and how those engagements themselves participate in the building of identities. ${ }^{4}$ The specific analysis

\footnotetext{
1 This chapter revisits and reworks a paper previous published as: M. Pickersgill, "The Co-production of Science, Ethics and Emotion', (2012) Science, Technology \& Human Values, 37(6), 579-603. Data are reproduced by kind permission of the journal and content used by permission of the publisher, SAGE Publications, Inc.

${ }^{2}$ M. M. Easter et al., 'The Many Meanings of Care in Clinical Research', (2006) Sociology of Health ङ Illness, 28(6), 695-712; U. Felt et al., 'Unruly Ethics: On the Difficulties of a Bottom-up Approach to Ethics in the Field of Genomics', (2009) Public Understanding of Science, 18(3), 354-371; A. Hedgecoe, 'Context, Ethics and Pharmacogenetics', (2006) Studies in History and Philosophy of Biological and Biomedical Sciences, 37(3), 566-582; A. Hedgecoe and P. Martin, 'The Drugs Don't Work: Expectations and the Shaping of Pharmacogenetics', (2003) Social Studies of Science, 33(3), 327-364; B. Salter 'Bioethics, Politics and the Moral Economy of Human Embryonic Stem Cell Science: The Case of the European Union's Sixth Framework Programme', (2007) New Genetics ש Society, 26(3), 269-288; S. Sperling, 'Managing Potential Selves: Stem Cells, Immigrants, and German Identity', (2004) Science \& Public Policy, 31(2), 139-149; M. N. Svendsen and L. Koch, 'Between Neutrality and Engagement: A Case Study of Recruitment to Pharmacogenomic Research in Denmark’, (2008) BioSocieties, 3(4), 399-418; S. P. Wainwright et al., 'Ethical Boundary-Work in the Embryonic Stem Cell Laboratory', (2006) Sociology of Health E Illness, 28(6), 732-748.

3 M. Pickersgill, 'From "Implications" to "Dimensions": Science, Medicine and Ethics in Society', (2013) Health Care Analysis, 21(1), 31-42.

4 C. Waterton and B. Wynne, 'Can Focus Groups Access Community Views?' in R. S. Barbour and J. Kitzinger (eds), Developing Focus Group Research: Politics, Theory and Practice (London: Sage, 1999), pp. 127-143, 142. The methodology of these focus groups is more fully described in the following: M. Pickersill et al., 'Constituting Neurologic Subjects: Neuroscience, Subjectivity and the Mundane Significance of the Brain', (2011) Subjectivity, 4(3), 346-365;
} 
presented is informed by the work of science and technology studies (STS) scholar Sheila Jasanoff and other social scientists who have highlighted the intertwinement of knowledge with social order and practices. ${ }^{5}$ In what follows, I explore issues that the neuroscientists I spoke with deem to be raised by their work, and characterise how both informal ideas about ethics and formal ethical governance (e.g. RECs) are experienced and linked to their research. In doing so, I demonstrate some of the lived realities of scientists who must necessarily grapple with the heterogenous forms of health-related research regulation the editors of this volume highlight in their Introduction, while seeking to conduct research with epistemic and social value. ${ }^{6}$

\subsection{NEGOTIATING THE ETHICAL DIMENSIONS OF NEUROSCIENCE}

It is well known that scientists are not lovers of the bureaucracies of research management, which are commonly taken to include the completion of ethical review forms. This was a topic of discussion in the focus groups: one scientist, for instance, spoke of the 'dread' ( $\mathrm{M}_{3}$, Group 5) felt at the prospect of applying for ethical approvals. Such an idiom will no doubt be familiar to many lawyers, ethicists and regulatory studies scholars who have engaged with life scientists about the normative dimensions of their work.

Research governance - specifically, ethical approvals - could, in fact, be seen as having the potential of hampering science, without necessarily making it more ethical. In one focus group (Group 1), three postdoctoral neuroscientists discussed the different terms ethics committees had asked them to use in recruitment materials. One scientist $\left(\mathrm{F}_{3}\right)$ expressed irritation that another $\left(\mathrm{F}_{2}\right)$ was required to alter a recruitment poster, in order that it clearly stated that participants would receive an 'inconvenience allowance' rather than be 'paid'. The scientists did not think that this would facilitate recruitment into a study, nor enable it to be undertaken any more ethically. $F_{3}$ described how 'it's just so hard to get subjects. Also if you need to get subjects from the general public, you know, you need these tricks'. It was considered that changing recruitment posters would not make the research more ethical - but it might prevent it happening in the first place.

All that being said, scientists also feel motivated to ensure their research is conducted 'ethically'. As the power of neuroimaging techniques increases, it is often said that it becomes all the more crucial for neuroscientists to engage with ethical questions. ${ }^{7}$ The scientists in my focus groups shared this sentiment, commonly expressed by senior scientists and ethicists. As one participant reflected, 'the ethics and management of brain imaging is really becoming a very key feature of $[. .$.$] everyday imaging' ( F_{2}$, Group 4). Another scientist ( $F_{1}$, Group 2) summarised the perspectives expressed by all those who participated in the focus groups:

I think the scope of what we can do is broadening all the time and every time you find out something new, you have to consider the implications on your [research] population.

M. Pickersgill et al., 'The Changing Brain: Neuroscience and the Enduring Import of Everyday Experience', (2015), Public Understanding of Science, 24(7), 878-892; Pickersgill, 'The Co-production of Science'.

5 S. Jasanoff, S. (ed.) States of Knowledge: The Co-Production of Science and Social Order, Oxford (Routledge, 2004), PP. 1-12; P. Brodwin, 'The Coproduction of Moral Discourse in US Community Psychiatry', (2008) Medical Anthropology Quarterly, 22(2), 127-147.

${ }^{6}$ See Introduction of this volume; A. Ganguli-Mitra, et al., 'Reconfiguring Social Value in Health Research through the Lens of Liminality', (2017) Bioethics, 31(2), 87-96.

7 M. J. Farah, 'Emerging Ethical Issues in Neuroscience', (2002) Nature Neuroscience, 5(11), 1123-1129; T. Fuchs, 'Ethical Issues in Neuroscience', (2006) Current Opinion in Psychiatry, 19(6), 600-607; J. Illes and É. Racine, 'Imaging or Imagining? A Neuroethics Challenge Informed by Genetics', (2005) American Journal of Bioethics, 5(2), $5^{-18 .}$ 
What scientists consider to be sited within the territory of the 'ethical' is wide-ranging, underscoring the scope of neuroscientific research, and the diverse institutional and personal norms through which it is shaped and governed. One researcher $\left(\mathrm{F}_{1}\right.$, Group 2$)$ reflected that ethical research was not merely that which had been formally warranted as such:

I think when I say you know 'ethical research', I don't mean research passed by an ethics committee I mean ethical to what I would consider ethical and I couldn't bring myself to do anything that I didn't consider ethical in my job even if it's been passed by an ethics committee. I guess researchers should hold themselves to that standard.

Conflicts about what was formally deemed ethical and what scientists felt was ethical were not altogether rare. In particular, instances of unease and ambivalence around international collaboration were reflected upon in some of the focus group discussions. Specifically, these were in relation to collaboration with nations that the scientists perceived as having relatively lax ethical governance as compared to the UK. This could leave scientists with a 'slight uneasy feeling in your stomach' ( $\mathrm{F}_{2}$, Group 4). Despite my participants constructing some countries as being more or less 'ethical', no focus group participant described any collaborations having collapsed as a consequence of diverging perspectives on ethical research. However, the possibility that differences between nations exist, and that these difference could create problems in collaboration, was important to the scientists I spoke with. There was unease attached to collaborating with a 'country that doesn't have the same ethics' ( $F_{2}$, Group 4). To an extent, then, an assumption of a shared normative agenda seemed to have significance as an underpinning for cross-national team science.

The need to ensure confidentiality while also sharing data with colleagues and collaborators was another source of friction. This was deemed to be a particularly acute issue for neuroscience, since neuroimaging techniques were seen as being able to generate and collect particularly sensitive information about a person (given both the biological salience of the brain and the role of knowledge about it in crafting identities). ${ }^{8}$ The need to separate data from anything that could contribute to identifying the human subject it was obtained from impacted scientists' relationships with their research. In one focus group (Group 3), $\mathrm{M}_{3}$ pointed out that no longer were scientists owners of data, but rather, they were responsible chaperones for it.

Fears were expressed in the focus groups that neuroscientific data might inadvertently impact upon research participants, for instance, affecting their hopes for later life, legal credibility and insurance premiums. Echoing concerns raised in both ethics and social scientific literatures, my participants described a wariness about any attempt to predict 'pathological' behaviours, since this could result in the 'labelling' ( $F_{1}$, Group 4) or 'compartmentalising' ( $F_{2}$, Group 4) of people. 9 As such, these scientists avoided involving themselves in research that necessarily entailed children, prisoners, or 'vulnerable people' ( $F_{2}$, group 4). Intra-institutional tensions could emerge when colleagues were carrying out studies that the scientists I spoke with did not regard as ethically acceptable.

Some focus group participants highlighted the hyping of neuroscience, and argued that it was important to resist this. ${ }^{10}$ These scientists nevertheless granted the possibility that some of the

\footnotetext{
8 E. Postan, 'Defining Ourselves: Personal Bioinformation as a Tool of Narrative Self-conception', Journal of Bioethical Inquiry, 13(1), 133-151. See also Postan, Chapter 23 in this volume.

9 Farah, 'Emerging Ethical Issues'; Illes and Racine, 'Imaging or Imagining?'; M. Gazzaniga, The Ethical Brain (Chicago: Dana Press, 2005).

${ }^{10}$ Hedgecoe and Martin, 'The Drugs Don't Work', 8.
} 
wilder promises made about neuroscience (e.g. 'mind reading') could one day be realised generating ethical problems in the process:

there's definitely a lot of ethical implications on that in terms of what the average person thinks that these methods can do and can't do, and what they actually can do. And if the methods should get to the point where they could do things like that, to what extent is it going to get used in what way. ( $\mathrm{F}_{1}$, group 1$)$

Scientists expressed anxiety about 'develop[ing] your imaging techniques' but then being unable to 'control' the application of these ( $\mathrm{F}_{2}$, Group 4). Yet, not one of my participants stated that limits should be placed on 'dangerous' research. Developments in neuroscience were seen neither as intrinsically good nor as essentially bad, with nuclear power sometimes invoked as a similar example of how, to their mind, normativity adheres to deployments of scientific knowledge rather than its generation. More plainly: the rightness or wrongness of new research findings were believed to 'come down to the people who use it' ( $F_{1}$, Group 1), not to the findings per se. Procedures almost universally mandated by RECs were invoked as a way of giving licence to research: 'a good experiment is a good experiment as long as you've got full informed consent, actually!' ( $F_{1}$, Group 3). Another said:

I think you can research any question you want. The question is how you design your research, how ethical is the design in order to answer the question you're looking at. (F2, Group 2)

Despite refraining from some areas of work themselves, due to the associated social and ethical implications my participants either found it difficult to think of anything that should not be researched at all, or asserted that science should not treat anything as 'off-limits'. One scientist laughed in mock horror when asked if there were any branches of research that should not be progressed: 'Absolutely not!' (F1 Group 3). This participant described how 'you just can't stop research', and prohibitions in the UK would simply mean scientists in another country would conduct those studies instead. In this specific respect, ethical issues seemed to be somewhat secondary to the socially produced sense of competition that appears to drive forward much biomedical research.

\subsection{INCIDENTAL FINDINGS WITHIN NEUROIMAGING RESEARCH}

The challenge of what to do with incidental findings is a significant one for neuroscientists, and a matter that has exercised ethicists and lawyers (see Postan, Chapter 23 in this volume). ${ }^{11}$ They pose a particular problem for scientists undertaking brain imaging. Incidental findings have been defined as 'observations of potential clinical significance unexpectedly discovered in healthy subjects or in patients recruited to brain imaging research studies and unrelated to the purpose or variables of the study'. ${ }^{12}$ The possibilities and management of incidental findings were key issues in the focus group discussions I convened, with a participant in one group terming them 'a whole can of worms'

${ }^{11}$ T. C. Booth et al., 'Incidental Findings in "Healthy" Volunteers during Imaging Performed for Research: Current Legal and Ethical Implications', (2010) British Journal of Radiology, 83(990), 456-465; N. A. Scott et al., 'Incidental Findings in Neuroimaging Research: A Framework for Anticipating the Next Frontier', (2012) Journal of Empirical Research on Human Research Ethics, 7(1), 53-57; S. A. Tovino, 'Incidental Findings; A Common Law Approach', (2008) Accountability in Research, 15(4), 242-261.

${ }^{12}$ J. Illes et al., 'Incidental Findings in Brain Imaging Research', Science, 311(5762), 783-784, 783 . 
$\left(\mathrm{F}_{1}\right.$, Group 3). Another scientist reflected on the issue, and their talk underscores the affective dimensions of ethically challenging situations:

I remember the first time [I discovered an incidental finding] 'cos we were in the scanner room we were scanning the child and we see it online basically, that there might be something. It's a horrible feeling because you then, you obviously at this point you know the child from a few hours, since a few hours already, you've been working with the child and it's ... you have a personal investment, emotional investment in that already but the important thing is then once the child comes out of the scanner, you can't say anything, you can't let them feel anything, you know realise anything, so you have to be just really back to normal and pretend there's nothing wrong. Same with the parents, you can't give any kind of indication to them at all until you've got feedback from an expert, which obviously takes so many days, so on the day you can't let anything go and no, yeah it was, not a nice experience. ( $F_{2}$, Group 2)

Part of the difficulties inherent in this ethically (and emotionally) fraught area lies in the relationality between scientist and research subject. Brief yet close relationships between scientists and those they research are necessary to ensure the smooth running of studies. ${ }^{13}$ This intimacy, though, makes the management of incidental findings even more challenging. Further, the impacts of ethically significant issues on teamwork and collaboration are complex; for instance, what happens if incidental findings are located in the scans of co-workers, rather than previously unknown research subjects? One respondent described how these would be 'even more difficult to deal with' ( $F_{1}$, Group 1). Others reflected that they would refrain from 'helping out' by participating in a colleague's scan when, for instance, refining a protocol. This was due to the potential of neuroimaging to inadvertently reveal bodily or psychological information that they would not want their colleagues to know.

The challenge of incidental findings is one that involves a correspondence between a particular technical apparatus (i.e. imaging methods that could detect tumours) and an assemblage of normative imperatives (which perhaps most notably includes a duty of care towards research participants). This correspondence is reciprocally impactful: as is well known, technoscientific advances shift the terrain of ethical concern - but so too does the normative shape the scientific. In the case of incidental findings, for example, scientists increasingly felt obliged to cost in an (expensive) radiologist into their grants, to inspect each participant's scan; a scientist might 'feel uncomfortable showing anybody their research scan without having had a radiologist look at it to reassure you it was normal' ( $\mathrm{F}_{1}$, Group 3). Hence, 'to be truly ethical puts the cost up' ( $F_{2}$, Group 4). Not every scientist is able to command such sums from funders, who might also demand more epistemic bang for the buck when faced with increasingly costly research proposals. What we can know is intimately linked to what we can, and are willing to, spend. And if being 'truly ethical' indeed 'puts the cost up', then what science is sponsored, and who undertakes this, will be affected.

\subsection{NORMATIVE UNCERTAINTIES IN NEUROSCIENCE}

Scientific research using human and animal subjects in the UK is widely felt to be an amply regulated domain of work. We might, then, predict that issues like incidental findings can be

13 S. Cohn, 'Making Objective Facts from Intimate Relations: The Case of Neuroscience and Its Entanglements with Volunteers', (2008) History of the Human Sciences, 21(4), 86-103; S. Shostak and M. Waggoner, 'Narration and Neuroscience: Encountering the Social on the "Last Frontier of Medicine”, in M. D. Pickersill and I. van Keulen, (eds), Sociological Reflections on the Neurosciences (Bingley: Emerald, 2011), pp. 51-74. 
rendered less challenging to deal with through recourse to governance frameworks. Those neuroscientists who exclusively researched animals indeed regarded the parameters and procedures defining what was acceptable and legal in their work to be reasonable and clear. In fact, strict regulation was described as enjoining self-reflection about whether the science they were undertaking was 'worth doing' ( $F_{1}$, Group 6). This was not, however, the case for my participants working with humans. Rather, they regarded regulation in general as complicated, as well as vague: in the words of two respondents, 'too broad' and 'open to interpretation' ( $F_{1}$, Group 2), and 'a bit woolly' and 'ambiguous' ( $\mathrm{F}_{2}$, group 2). Take, for instance, the Data Protection Act: in one focus group (Group 3 ) a participant $\left(\mathrm{F}_{1}\right)$ noted that a given university would take their own view' about what was required by the Act, with different departments and laboratories in turn developing further - potentially diverging - interpretations.

Within the (neuro)sciences, procedural ambiguity can exist in relation to what scientists, practically, should do - and how ethically valorous it is to do so. Normative uncertainty can be complicated further by regulatory multiplicity. The participants of one focus group, for example, told me about three distinct yet ostensibly nested ethical jurisdictions they inhabited: their home department of psychology, their university medical school and their local National Health Service Research Ethics Committee (NHS REC). The scientists I spoke with understood these to have different purviews, with different procedural requirements for research, and different perspectives on the proper way enactment of ethical practices, such as obtaining informed consent in human subjects research.

Given such normative uncertainty, scientists often developed what we might term 'ethical workarounds'. By this, I mean that they sought to navigate situations where they were unsure of what, technically, was the 'right' thing to do by establishing their own individual and community norms for the ethical conduct of research, which might only be loosely connected to formal requirements. In sum, they worked around uncertainty by developing their own default practices that gave them some sense of surety. One participant ( $F_{1}$, Group 2$)$ described this in relation to drawing blood from people who took part in her research. To her mind, this should be attempted only twice before being abandoned. She asserted that this was not formally required by any research regulation, but instead was an informal standard to which she and colleagues nevertheless adhered.

In the same focus group discussion, another scientist articulated a version of regulatory underdetermination to describe the limits of governance:

not every little detail can be written down in the ethics and a lot of it is in terms of if you're a researcher you have to you know make your mind up in terms of the ethical procedures you have to adhere to yourself and what would you want to be done to yourself or not to be done... ( $\mathrm{F}_{2}$, Group 2 )

Incidental findings were a key example of normative uncertainty and the ethical workarounds that resulted from this. Although 'not every little detail can be written down', specificity in guidelines can be regarded as a virtue in research that is seen to have considerable ethical significance, and where notable variations in practice were known to exist. The scientist quoted above also discussed how practical and ethical decisions must be made as a result of the detection of clinically relevant incidental findings, but that their precise nature was uncertain: scientists were 'struggling' due to being 'unsure' what the correct course of action should be. Hence, 'proper guidelines' were invoked as potentially useful, but these were seemingly considered to be hard to come by.

The irritations stimulated by a perceived lack of clarity on the ethically and/or legally right way to proceed are similarly apparent in the response of this scientist to a question about her 
feelings upon discovering, for the first time, a clinically relevant incidental finding in the course of her neuroimaging work:

It was unnerving! And also because it was the first time I wasn't really sure how to deal with it all, so I had to go back in the, see my supervisor and talk to them about it and, try to find out how exactly we're dealing now with this issue because I wasn't aware of the exact clear guidelines. ( $\mathrm{F}_{2}$, Group 2)

Different scientists and different institutions were reported to have 'all got a different way of handling' ( $\mathrm{F}_{2}$, Group 4) the challenge of incidental findings. Institutional diversity was foregrounded, such as in the comments of $F_{1}$ (Group 1). She described how when working at one US university "there was always a doctor that had to read the scans so it was just required'. She emphasised how there was no decision-making around this on behalf of the scientist or the research participant: it was simply a requirement. On the other hand, at a different university this was not the case - no doctor was on call to assess neuroimages for incidental findings.

An exchange between two researchers ( $\mathrm{F}_{1}$ and $\mathrm{F}_{2}$, Group 2) also illustrates the problems of procedural diversity. Based in the same university but in different departments, they discussed how the complexities of managing incidental findings was related, in part, to practices of informed consent. Too lengthy a dialogue to fully reproduce here, two key features stood out. First, differences existed in whether the study team would, in practice, inform a research subject's physician in the event of an individual finding: in $\mathrm{F}_{2}$ 's case, it was routine for the physician to be contacted, but F1's participants could opt out of this. However, obtaining physician contact details was itself a tricky undertaking:

we don't have the details of the GP so if we found something we would have to contact them [the participant] and we'd have to ask them for the GP contact and in that case they could say no, we don't want to, so it's up to them to decide really, but we can't actually say anything directly to them what we've found or what we think there might be because we don't know, 'cos the GP then will have to send them to proper scans to determine the exact problem, 'cos our scans are obviously not designed for any kind of medical diagnosis are they? So I suppose they've still got the option to say no. ( $\mathrm{F}_{2}$, Group 2)

It is also worth noting at this point the lack of certitude of the scientists I spoke with about where directives around ethical practice came from, and what regulatory force these had. F1 (Group 1) and $\mathrm{F}_{2}$ (Group 2) above, for instance, spoke about how certain processes were 'just required' or how they 'have to' do particular things to be 'ethical'. This underscores the proliferation and heterogeneity of regulation the editors of this volume note in their Introduction, and the challenges of comprehending and negotiating it in practice by busy and already stretched professionals.

\subsection{DISCUSSION}

The ethical aspects of science often require discursive and institutional work to become recognised as such, and managed thereafter. In other words, for an issue to be regarded as specifically ethical, scientists and universities need to, in some sense, agree that it is; matters that ethicists, for instance, might take almost for granted as being intrinsically normative can often escape the attention of scientists themselves. After an issue has been characterised by researchers as ethical, addressing it can necessitate bureaucratic innovation, and the reorganisation of work 
practices (including new roles and changing responsibilities). Scientists are not always satisfied with the extent to which they are able, and enabled, to make these changes. The ethics of neuroscience, and the everyday conversations and practices that come into play to deal with them, can also have epistemic effects: ethical issues can and do shape scientists relationships with the work, research participants, and processes of knowledge-production itself.

The scientists I spoke with listed a range of issues as having ethical significance, to varying degrees. Key among these were incidental findings. The scientists also engaged in what sociologist Steven Wainwright and colleagues call 'ethical boundary work'; i.e. they sometimes erected boundaries between scientific matters and normative concerns, but also collapsed these when equating good science with ethical science. ${ }^{14}$ This has the effect of enabling scientists to present research they hold in high regard as being normatively valorous, while also bracketing off ethical questions they consider too administratively or philosophical challenging to deal with as being insufficiently salient to science itself to necessitate sustained engagement.

Still, though, ethics is part and parcel of scientific work and of being a scientist. Normative reflection is, to varying degrees, embedded within the practices of researchers, and can surface not only in focus group discussions but also in corridor talk and coffee room chats. This is, in part, a consequence of the considerable health-related research regulation to which scientists are subject. It is also a consequence of the fact that scientists are moral agents: people who live and act in a world with other persons, and who have an everyday sense of right and wrong. This sense is inevitably and essentially context-dependent, and it inflects their scientific practice and will be contoured in turn by this. It is these interpretations of regulation in conjunction with the mundane normativity of daily life that intertwine to constitute scientists' ethical actions within the laboratory and beyond, and in particular that cultivate their ethical workarounds in conditions of uncertainty.

\subsection{CONCLUSION}

In this chapter I have summarised and discussed data regarding how neuroscientists construct and regard the ethical dimensions of their work, and reflected on how they negotiate healthrelated research regulation in practice. Where does this leave regulators? For a start, we need more sustained, empirical studies of how scientists comprehend and negotiate the ethical dimensions of their research in actual scientific work, in order to ground the development and enforcement of regulation. ${ }^{15}$ What is already apparent, however, is that any regulation that demands actions that require sharp changes in practice, to no clear benefit to research participants, scientists, or wider society, is unlikely to invite adherence. Nor are frameworks that place demands on scientists to act in ways they consider unethical, or which place unrealistic burdens (e.g. liaising with GPs without the knowledge of research participants) on scientists that leave them anxious and afraid that they are, for instance, 'breaking the law' when failing to act in a practically unfeasible way.

It is important to recognise that scientists bring to bear their everyday ethical expertise to their research, and it is vital that this is worked with rather than ridden over. At the same time, it takes

${ }^{14}$ Wainwright et al., 'Ethical Boundary-Work'.

15 M. Pickersgill et al., 'Biomedicine, Self and Society: An Agenda for Collaboration and Engagement', (2019) Wellcome Open Research, 4(9). 
a particular kind of scientist to call into question the ethical basis of their research or that of close colleagues, not least given an impulse to conflate good science with ethical science. Consequently, developing regulation in close collaboration with scientists also needs the considered input of critical friends to both regulators and to life scientists (including but not limited to social scientific observers of the life sciences). This would help mitigate the possibility of the inadvertent reworking or even subverting of regulation designed to protect human subjects by well-meaning scientists who inevitably want to do good (in every sense of the word) research. 